\title{
En busca de la voz de los herederos de la Revolución. Un análisis de los documentos producidos por los niños, 1921-1940
}

\author{
Elena Jackson Albarrán* \\ MIAMI UNIVERSITY OF OHIO
}

El objetivo de este artículo es identificar y describir algunas ventajas y problemas asociados con el uso de documentos históricos producidos por los niños durante los años posrevolucionarios en México. La historia de la niñez siempre ha estado sujeta a las interpretaciones de los adultos y, generalmente, lo que sabemos de su pasado viene a través de documentos provenientes de las instituciones de bienestar, las agencias gubernamentales, los maestros y familiares. Sin embargo, en las primeras décadas del siglo $\mathrm{xx}$, los programas revolucionarios y nuevos impulsos tecnológicos en las comunicaciones masivas abrieron más espacios para la participación social y cívica de los niños. En este ambiente político y cultural, los niños dejaron sus huellas documentadas. Para escribir una historia de la infancia, es imperativo integrar los documentos producidos por los niños para iluminar su papel como agentes históricos.

(Niñez, producciones culturales infantiles, SEP, posrevolución, agencia)

\section{INTRODUCCIÓN}

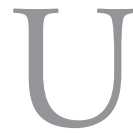

na mańana de septiembre de 1926, niños capitalinos de varias escuelas se levantaron a las cuatro de la madrugada para encontrarse en el andén de la parada del tren en Coyoacán y partir hacia una excursión a Miraflores. Este viaje era una experiencia única, que se otorgaba cada mes a algunos dichosos niños por destacarse en sus clases de dibujo. Los viajes eran patrocinados por el maestro Juan Olaguíbel, oficial de la Secretaría de

*albarrej@muohio.edu 
Educación Pública (SEP) y director de la revista infantil gratuita Pulgarcito, órgano de esa misma secretaría y parte de una iniciativa educativa para exponer a los precoces artistas de la capital la belleza de su patria en su más "auténtica" representación: el campo. El niño José Víctor Silva describió la excursión, en un ensayo publicado en la revista:

Como treinta alumnos de varias escuelas al cuidado de tres maestros, íbamos en tren. Primero no nos conocíamos, pero poco a poco nos fuimos haciendo amigos hasta el grado de parecer condiscípulos de un solo plantel... [al final de la excursión] cuando empezaba a caminar el tren seguíamos todos haciendo nuestros apuntes para llevarlos a nuestras casas, enseñarlos a nuestras familias, y con los colores que nos proporcionaron los profesores de dibujo, hacer en grande nuestros trabajos que hoy vemos expuestos en uno de los salones de la Secretaría de Educación Pública. ¡Ojalá salgan publicados en la Revista Pulgarcito! ${ }^{1}$

Con estas sencillas palabras, José Víctor declara las emociones que sintieron muchos niños en la década de 1920 y 1930 al aprovechar las aumentadas ofertas culturales que les brindaba el gobierno revolucionario con fines de fomentar experiencias comunes entre los nińos mexicanos. En el breve espacio de una excursión, los treinta nińos participantes en este evento compartían el paisaje, la tarea y el viaje de ida y vuelta. Poco después, se reunieron virtualmente, a través de la exposición de sus dibujos en los salones de la SEP, en esa novedosa experiencia extraescolar expuesta a la vista pública.

Justo como esperaba el pequeño autor, los dibujos de José Víctor y sus compańeros, los productos tangibles de un día de aventura y amistad, acompañaron su ensayo descriptivo en la publicación de Pulgarcito. Las palabras y los dibujos desarrollados por los niños, no sólo congelaron en el tiempo la memoria infantil de una experiencia fugaz, sino también sirvieron para inspirar a los niños lectores de la revista, en 1926, a sobresalir en sus respectivas clases de dibujo para alcanzar la fama y el reconocimiento público que disfrutaba

${ }^{1}$ Pulgarcito, año II, núm. 18, octubre de 1926, 25-6. 
José Víctor y, quizás, ganar uno de los codiciados viajes con el profesor Olaguíbel para dibujar el paisaje rural mexicano.

La composición y los dibujos forman un ejemplo de los artefactos que nos quedan de las infancias de millones de niños mexicanos que crecieron durante la posrevolución. A través de su colaboración en Pulgarcito, niños como José Víctor contribuían al conocimiento cultural, la educación y el entretenimiento de sus compañeros y compatriotas. Sus sencillas palabras y sus dibujos rudimentarios, en conjunto con los varios documentos producidos por otros niños durante las décadas posteriores a la revolución, facilitan al historiador una herramienta para medir su nivel de interés y entendimiento de los procesos políticos, culturales y sociales que les rodeaban. Los documentos producidos por los niños, lejos de ser una simple diversión para el archivista, permiten interpretar la historia desde la perspectiva de un grupo poco estudiado pero a la vez muy presente durante estos años transcendentales.

\section{LA HISTORIA CONTADA DESDE LA PERSPECTIVA DE LOS NIÑOS}

La educación en México recibió un impulso extraordinario después de la Revolución. La SEP fue la agencia gubernamental con el mayor presupuesto durante los ańos 1920-1940, contando con un promedio del diez por ciento de los gastos oficiales en ese periodo. ${ }^{2}$ Los aumentados recursos coincidieron con una nueva pedagogía que promovió el concepto del nińo activo, culminando con una oleada de fuentes producidas por los niños en las escuelas primarias, o a través de proyectos culturales relacionados con el programa educativo de la SEP. Encabezada por José Vasconcelos en los primeros ańos posrevolucionarios y caracterizada por su tremenda energía dedicada a la implementación de una educación primaria obligatoria y gratuita para todos los mexicanos, la SEP se expandió a todos los rincones del país en forma de maestros rurales, misioneros culturales y nuevas edificaciones públicas que garantizarían el espacio físico

${ }^{2}$ James W. Wilkie, The Mexican Revolution: Federal Expenditure and Social Change since 1910, Revised Edition, Berkeley, University of California Press, 1970, 160-161. 
para la enseñanza del nacionalismo cultural. ${ }^{3}$ Ya empezada la iniciativa cardenista de educación socialista en 1934, producto de una modificación del artículo $3^{\circ}$ de la constitución, la visibilidad del niño en el ámbito cívico se acrecentó aun más, dada la valoración pública prestada al trabajo agrario, doméstico y comercial del niño proletario como complemento a su educación. Existen entonces sobre estos años más fuentes históricas infantiles producidas no sólo por los burócratas y funcionarios del gobierno, sino también por los niños que formaban parte de la nueva escuela mexicana.

Antes de esta época, la voz del niño se grabó en la historia en muy pocas ocasiones. En su mayoría, los niños no aparecían en los documentos históricos a menos que fueran abandonados, maltratados, encarcelados, castigados, explotados o asesinados. Estos niños aparecen como parte de la historia institucional, sujetos a los poderes coloniales, religiosos, gubernamentales, o simplemente a los adultos que regían sus días. Algunos historiadores han lamentado la "invisibilidad" del niño como parte de la sociedad debido a la ausencia de su voz en la historia. ${ }^{4}$ En la historiografía mexicana se está abriendo un campo de estudio de la historia de la infancia, en la que las experiencias de los niños se descubren por un análisis de la política estatal; las instituciones educativas, correccionales y de caridad; y las producciones culturales destinadas a los niños. ${ }^{5}$ Algunos exce-

${ }^{3}$ Ernesto Meneses Morales, Tendencias educativas oficiales en México, 1911-1934. La problemática de la educación mexicana durante la Revolución y en los primeros lustros de la época posrevolucionaria, México, Centro de Estudios Educativos, Instituto Iberoamericano, 1998; Claude Fell, José Vasconcelos: los años del águila. Educación, cultura e iberoamericanismo en el México postrevolucionario, serie de historia moderna y contemporánea 21, México, Universidad Nacional Autónoma de México, 1989; David L. Raby y Martha Donís, "Ideología y construcción del Estado: la función política de la educación rural en México, 1921-1935”, Revista Mexicana de Sociología, vol. 5, núm. 2, Visiones de México, abril-junio de 1989, 305-320.

${ }^{4}$ Francisco Pilotti, "Crise e perspectives da assistência à infância na América Latina", en Francisco Pilotti e Irene Rizzini, orgs., A arte de governor crianças: A história das politicas sociais, da legislação e da assistência à infância no Brasil, Río de Janeiro, Instituto Interamericano del Niño, 1995, 25-26.

${ }^{5}$ Susana Sosenski, Niños en acción: el trabajo infantil en la ciudad de México, 19201934, México, El Colegio de México, 2010 e "Infancia y familia posrevolucionaria", Legajos: Boletín del Archivo General de la Nación, $7^{\text {a }}$ época, núm. 1, julio-septiembre 2009, 10-21; Ann Shelby Blum, Domestic Economies: Family, Work and Welfare in Mexico 
lentes estudios sitúan al niño en el centro del discurso histórico; por ejemplo, Ann Blum argumenta que la fisicalidad del cuerpo infantil se hizo sinónimo con la salud de la Gran Familia Revolucionaria a partir del Primer Congreso Mexicano del Niño en 1921, lo que se manifestó en una proliferación de concursos (del Niño Bonito y el Niño Sano, por ejemplo). ${ }^{6}$

Otra táctica histórica efectiva, y una labor intensiva, ha sido recopilar las memorias de los adultos que vivieron los años posrevolucionarios a partir de la historia oral. Las memorias describen las experiencias cotidianas, recapturan los detalles perdidos de una época y prestan una textura sensorial a las narrativas institucionales. ${ }^{7}$ Pero la memoria, como todas las fuentes históricas, sufre los filtros de los años y los prejuicios adultos de hoy en día. Nos acercan a la infancia posrevolucionaria y tienen un valor indescriptible, sin embargo, no es paralela al poder de un documento que contiene la impresión de una experiencia dejada por un niño en el momento en que la vive. Estas historias han enriquecido enormemente nuestro entendimiento de los efectos de las reformas revolucionarias en la población infantil, que podría decirse la población más visible en la mirada de los oficiales educativos revolucionarios. El contexto histórico que abarca esta tendencia académica nos abre caminos para descifrar e interpretar los documentos que esos mismos nińos producían como resultado de su participación en las crecientes oportunidades cívicas, educativas y sociales durante la posrevolución.

City, 1884-1943, Lincoln, University of Nebraska Press, 2010 y "Breaking and Making Families: Adoption and Public Welfare, Mexico City, 1938-1942”, en Jocelyn Olcott, Mary Kay Vaughan, Gabriela Cano, eds., Sex in Revolution: Gender, Politics and Power in Modern Mexico, Durham, Duke University Press, 2006, 127-146.

${ }^{6}$ Ann Shelby Blum, Domestic Economies..., 2010, 129-181.

${ }^{7}$ Véase, por ejemplo, Engracia Loyo B., "En el aula y la parcela: vida escolar en el medio rural (1921-1940)", en Aurelio de los Reyes, ed., Historia de la vida cotidiana en México. Siglo XX. Campo y ciudad, tomo v, vol. 1, México, El Colegio de México, Fondo de Cultura Económica, 2006, 273-312. Vale la pena destacar también las transcripciones de entrevistas con maestras y estudiantes de la escuela rural, en el Archivo de la Palabra del Instituto de Investigaciones Dr. José Ma. Luis Mora. Otra fuente de interés, y que contiene relatos de los maestros rurales relativos a sus experiencias en las escuelas, es Engracia Loyo Bravo, Cecilia Greaves y Valentina Torres, Los maestros y la cultura nacional, 1920-1950, 5 tomos, México, Museo Nacional de Culturas Populares, sEp, 1987. 
Hasta ahora, esta clase de producción histórica ha sido pasada por alto en favor de los dictámenes, discursos, publicaciones e inspecciones producidos por los adultos y, sobre todo, los gobernantes oficiales del Estado.

Sin embargo, en los últimos años ha surgido una nueva tendencia entre historiadores de la infancia del mundo occidental para escribir la historia desde la perspectiva de los niños, rescatando de los archivos las fuentes que ellos mismos crearon para interpretar sus experiencias como agentes, una versión de la historia cotidiana que no da prioridad a la perspectiva de los adultos ni a la historia institucional. Por ejemplo, en su estudio de una colección de libros en miniatura producidos por los niños de una familia estadounidense en el siglo XIx, Karen Sánchez-Eppler señala que el proceso de crear libritos según las reglas de las casas editoriales (pero con contenido y estilo de producción netamente infantiles) era una manera para que los niños "produjeran la autoridad cultural". Los libros, como documentos de su infancia ya pasada, combinaban el acto de jugar con una demostración del autoconocimiento de su socialización. ${ }^{8}$ Otro ejemplo instructivo demuestra el valor histórico de las cartas infantiles escritas al presidente estadounidense Herbert Hoover en los ańos entreguerras, descritas por Dominique Marshall. Niños de alrededor del mundo le daban las gracias a Hoover por su demostrado interés en los derechos de los niños; sus testimonios, muchos escritos a mano acompañados de tiernas y felices ilustraciones, daban evidencia de los verdaderos mejoramientos a la infancia mundial a causa de los actos políticos que promovía Hoover a favor de los pequeños. ${ }^{9}$ Rara vez el historiador encuentra un tesoro fabricado por manos infantiles, como lo encontró Daniel Cohen en una libreta irónica que se burla de las normas de higiene, escrito e ilustrado por

${ }^{8}$ Karen Sánchez-Eppler, "Practicing for Print: The Hale Children's Manuscript Libraries", Journal of the History of Childhood and Youth, vol. 1, núm. 2, primavera 2008, 188-209.

${ }^{9}$ Dominique Marshall, "Children's Rights and Children's Action in International Relief and Domestic Welfare: The Work of Herbert Hoover between 1914 and 1950", Journal of the History of Childhood and Youth, vol. 1, núm. 3, otoño 2008, 351-388. 
una niña estadounidense en los años treinta. ${ }^{10}$ Éstos son sólo algunos ejemplos del trabajo histórico que se ha hecho para rescatar la voz y la perspectiva infantil. De ahí que, dadas las condiciones favorables en los años posrevolucionarios en México para la participación infantil en la acción cívica, el ámbito cultural y la vida social, éstos sean un buen punto de partida para el presente esfuerzo.

A continuación veremos algunos ejemplos de tales fuentes infantiles, tomando en consideración los desafíos y las ventajas de trabajar con ellas, con el objetivo de formular un método de estudio de la cultura infantil desde el punto de vista de los niños. Vale la pena aquí señalar qué entendemos por niñez. Durante los años que nos interesan, la multitud de oportunidades para la acción cívica de niños y nińas se reflejaba tanto en su presencia visible en la vida cotidiana como en el lenguaje usado para describir las actividades. La identidad de los niños como ciudadanos -y de los pequeńos ciudadanos como niños- se reforzaba con la proliferación de organizaciones infantiles, producciones culturales de radio y teatro para niños y revistas infantiles. Para algunos jóvenes o adolescentes, sus vidas cotidianas no los diferenciaban de los adultos; sin embargo, la oportunidad de participar en una organización infantil les abría la posibilidad de una nueva identidad social. Además, el concepto de la juventud, que hoy en día entendemos que incluye los años de la adolescencia, apenas se concebía a principios del siglo xx y no emergería como un grupo social y culturalmente distinto sino hasta mediados del siglo. ${ }^{11}$ Entonces, en los años veinte y treinta, la identidad social de los menores de edad estaba sujeta a la interpretación individual, caso por caso. En este contexto, entendemos los términos "niño/a” y “joven" no como categorías biológicas, sino como posibles identidades fluidas que los respectivos miembros podrían elegir libremente.

${ }^{10}$ Daniel A. Cohen, "Rewriting The Token of Love: Sentimentalists, Sophisticates, and the Transformation of American Girlhood, 1862-1940", Journal of the History of Childhood and Youth, vol. 4, núm. 2, primavera 2011, 223-256.

${ }^{11}$ Katherine Elaine Bliss y Ann S. Blum, "Dangerous Driving: Adolescence, Sex, and the Gendered Experience of Public Space in Mexico City", en William E. French y Katherine Elaine Bliss, eds., Gender, Sexuality, and Power in Latin America since Independence, Lanham, Rowman \& Littlefield Publishers, Inc., 2007, 165-166. 
Una crítica que se levanta sobre las fuentes infantiles es que no se puede confiar en su autenticidad, dada la fuerte posibilidad de que hayan sido manipuladas por las ideas e influencias del mundo adulto que las rodeó. Con certeza, hay que admitir que toda la evidencia que encontramos de la participación cívica, política y social de los niños - las cartas, los dibujos, los discursos políticos, las entrevistas publicadas en los periódicos- da prueba de la presencia de los padres, maestros y administradores que regían los días de los pequeños. Además, como se demostrará a continuación, la sintaxis y las expresiones presentes en los documentos (por ejemplo, el lenguaje burocrático y formal usado por los niños en las cartas escritas a los oficiales gubernamentales) muestran la internalización de parte de los nińos de una enseñanza explícita de las normas de la correspondencia oficial. El vocabulario socialista sumamente ideológico, supuestamente redactado por los nińos proletarios durante su congreso de 1935, representa para el historiador no una expresión espontánea de la conciencia de clase social, sino una especie de adoctrinamiento pedagógico.

Sin embargo, sostengo que todo tipo de documento histórico sufre la mediación de familiares, superiores, gobernantes, administradores o archivistas antes de llegar a las manos de los historiadores. Nuestra tarea es separarlo de sus capas de influencias ajenas para examinar -en la medida de lo posible- las distintas influencias e intervenciones de los adultos y las convenciones sociales que rigen la producción cultural infantil, siempre con una sensibilidad al contexto histórico y personal que contribuye a su formación. El valor de escribir la historia desde la perspectiva de los niños, no obstante los notables retos que eso presenta, no puede ser exagerado. La historiadora Karen Sánchez-Eppler nos recuerda de la imposibilidad de separar, por completo, la investigación de las experiencias infantiles de los deseos y manipulaciones de los adultos. ${ }^{12}$ De todos los grupos

${ }^{12}$ Karen Sánchez-Eppler, Dependent States: The Child's Part in Nineteenth-Century American Culture, Chicago, University of Chicago Press, 2005, xvii. 
sociales, los niños tienden a ser los más transparentes y los menos filtrados en sus reacciones a su cambiante ámbito cultural. Como bien sugiere el académico Stephen Kline, dondequiera que los niños se reúnan e interactúen, surgen expresiones espontáneas de autoexpresión, aun cuando sus reuniones e interacciones se sometan paulatinamente a la intervención, o sobreinstrucción, de los adultos. ${ }^{13}$ A la vez que los niños tienden a ser un espejo casi fiel de "los procesos de la civilización”, entre sus imitaciones del mundo adulto atestamos que insinúan vestigios de sus seres independientes, seres aún en el proceso de realización. Se trata de descifrar entre pistas, siempre y cuando sean visibles al ojo del historiador, y el resultado puede ser, en el mejor de los casos, revelador de una experiencia infantil fugaz. Dentro de pocos años de dejar su huella en la historia, los pequeńos autores y actores pasan al mundo adulto por lo que han estado ensayando todos en sus breves vidas. En el caso de los documentos producidos por los niños durante la posrevolución, esa labor de rescatar su voz nos provee con otra voz más en el creciente panorama de la experiencia social y cultural de los mexicanos en las décadas después de la Revolución.

Inicio ahora con la descripción de algunas de estas fuentes, junto con una breve discusión de cómo pueden ser útiles en la reconstrucción de la historia de la educación revolucionaria, protagonizada por los nińos destinatarios de las reformas estatales.

\section{NiÑOS POLÍ́TICOS: CARTAS Y PETICIONES A LAS AUTORIDADES REVOLUCIONARIAS}

Lo(s) que subscribimos, hijos de Sonora y miembros de la Sociedad de alumnos "Infantil Cultura" de la Escuela Of. Sup. Mixta de Huépac. Ya que los fines de nuestra agrupación son velar por los intereses de su colectividad y progreso de nuestra querida Patria, atenta y respetuosamente suplicamos a Ud. nos ayude, si a bien tiene, obsequiandonos unas piezas de géneros para vestir a nuestros socios huérfanos y pobres, pero que llenos

${ }^{13}$ Stephen Kline, “The Making of Children's Culture”, Henry Jenkins, ed., The Children's Culture Reader, Nueva York, New York University Press, 1998, 96. 
de voluntad asisten a la Escuela; unos libros de su agrado para enriquecer la BIBLIOTECA establecida por la misma Institución y juguetes para el mejor desarrollo de Cultura Física. Por dificultades de transporte, suplicamos remita nuestro pedido por express a Cananea, enviándonos el aviso para recogerlo. Perdone que el carácter de los Sonorenses sea franco y sincero. Nos anticipamos en dar a Ud. las gracias por su obsequio, manifestándole a la vez nuestros respetos.

Progreso y Unión.

Huépac. Son. 12 de febrero de 1925

La Presidenta

Srita. Belen Alegría (firmada también por más estudiantes). ${ }^{14}$

Esta carta, escrita por la presidenta Belén Alegría y dirigida al presidente Plutarco Elías Calles, señala uno de los grandes legados de la revolución: la difusión de un sentimiento popular de pertenencia a ese gran movimiento del pueblo y para el pueblo. La gente humilde experimentó una euforia, ya abierta a un nuevo espacio democrático, por breve y superficial que fuera. El entusiasmo por la participación política tomó la forma de una oleada de cartas que inundaban las oficinas de los gobernantes de la república. El populismo que caracterizó los diferentes gobiernos revolucionarios dio la impresión de democratizar la política popular; como resultado, la gente se sentía con el derecho de comunicarse directamente con el presidente, anunciando cualquier inquietud de la vida cotidiana. Tal vez Lázaro Cárdenas fue el primero en solicitar cartas directamente de sus ciudadanos, pero los presidentes Obregón, Calles, Rodríguez, Ortiz Rubio y Portes Gil también se ahogaban en las peticiones y solicitudes de los millones de mexicanos que por fin se sentían con derecho de una herencia revolucionaria. ${ }^{15}$

${ }^{14}$ Carta a Plutarco Elías Calles de la Sociedad de Niños "Infantil Cultura”, 12 de febrero de 1925, Archivo General de la Nación (AGN), fondo Obregón-Calles, expediente $805-\mathrm{H}-101$.

${ }^{15}$ Entre los que han escrito sobre las cartas a los presidentes revolucionarios, se encuentran: Josefina MacGregor, México de su puño y letra: el sentir de un pueblo en las cartas al presidente, México, Editorial Diana, 1993; y María del Carmen Nava Nava, Los abajo firmantes: cartas a los presidentes, México, SEP, Unidad de Publicaciones Educativas, Editorial Patria, 1994. 
Los niños no quedaban de lado en ese movimiento postal; durante los primeros ańos de los 1920, y aun más durante los años optimistas de la educación socialista, se encuentran cartas escritas a oficiales gubernamentales, facilitadas por las nuevas tecnologías de la máquina de escribir y la radio. ${ }^{16}$ Rápidamente, los niños aprendieron de la nueva cultura política y participaron en ella a su manera. La pequeńa presidenta Belén, en la carta arriba citada, ya empieza a utilizar el lenguaje burocrático ("atenta y respetuosamente suplicamos"); la retórica revolucionaria ("colectividad y progreso de nuestra querida Patria”); y las súplicas basadas en las identidades regionales que marcaban la política revolucionaria en sus tempranos años ("Perdone que el carácter de los Sonorenses sea franco y sincero"). Esta carta en particular revela que los niños se sentían con derecho de pedir de su compatriota sonorense, no tan sólo las necesidades, sino los útiles y bienes que servirían para llevar a cabo la prometida redistribución económica y hasta el programa educativo. La carta demuestra que Belén y sus colegas se apropiaron de la retórica de la Gran Familia Mexicana que surgía de la revolución y se sintieron con bastante confianza como para comunicarse directamente con Calles como una figura paternal que tenía la responsabilidad de responder a favor de su petición (no obstante, la respuesta emitida de las oficinas de Calles a esta petición fue negativa). El tono y el contenido de cartas como éstas demuestran una generación de niños con plena intención de participar en la posrevolución y las rutas que tomaron para acceder a las vías de poder político para cumplir sus misiones (hasta mandaron indicaciones específicas para el envío de los bienes, por "express", para poder cumplir con sus deberes a la brevedad).

Por lo general, las cartas infantiles representan las experiencias de los nińos de la clase media, urbana y relativamente privilegiada: los que tenían acceso al papel; los que sabían leer y escribir; los que disfrutaban el tiempo libre para sentarse y formular pensamientos escritos fuera del salón de clase; y los que podían pagar la estampilla

\footnotetext{
${ }^{16}$ Rubén Gallo, Mexican Modernity: The Avant-Garde and the Technological Revolution, Cambridge y Londres, The MIT Press, 2005.
} 
para mandarla por correo postal. Sin embargo, tenemos evidencia de que algunos niños, que no cabían directamente dentro de estas categorías, y aun así, vieron la palabra escrita y la burocracia revolucionaria como los mejores vehículos para pedir lo que según ellos se merecían como pequeños ciudadanos. Como mínimo, veían lo que les rodeaba en su mundo de la escuela y la comunidad, y querían participar en el mismo nivel que sus compatriotas en la nueva cultura infantil que les ofrecía el régimen revolucionario. En la medida de lo posible, la gente humilde (incluyendo a los niños) buscaban maneras de formalizar sus peticiones por vías tecnológicas y modernas. La máquina de escribir fue uno de los más importantes instrumentos para avanzar en la institucionalización y la burocratización de la revolución, formalizando las peticiones de hasta el más humilde de los solicitantes. ${ }^{17}$ La siguiente carta fue escrita a máquina por alumnos y alumnas de la Escuela Oficial Mixta "Emilio Carranza” de Sierra Mojada, Coahuila, al presidente Abelardo Rodríguez en 1932, y comparte algunos de los rasgos lingüísticos con la carta de la presidenta Belén:

Honorable Señor: Los que suscribimos esta petición ante usted señor Presidente, somos niños y nińas pertenecientes a la Escuela Oficial Mixta "Emilio Carranza", que deseosos y confiados en su benevolencia, hemos acordado elevar esta carta solicitando nuestra navidad.

Nos ha animado este propósito, en vista de la pobreza y penuria en que nuestros papacitos se encuentran, quienes carentes de trabajo, apenas y con innumerables sacrificios nos dan el pan cotidiano, pero en medio de esa tristeza nos consuela que en la actualidad gobierna a nuestra Patria un hombre muy bueno, sobre todo que ama a la juventud y velará porque muy pronto haya suficiente trabajo para nuestros padres para que por ese camino encontremos el verdadero progreso de nuestro querido México. Nuestros Profesores nos han enseñado a respetar el nombre de usted, señor Presidente, y por ellas os conocemos y tenemos esperanzas de consuelo en nuestro porvenir. Esto mismo nos fortaleció la idea de pedirle todos juntos nuestra Navidad, seguros de que seremos escuchados en nuestra demanda.

${ }^{17}$ Rubén Gallo, Mexican Modernity..., 2005, 69-70, 77, 91. 
Hacemos votos señor Presidente porque Dios os brinde sus bendiciones a Ud., a su honorable esposa e hijitos y porque os conceda muchos ańos de vida para bien de la Patria y de los Mexicanos, y enviando a Ud, nuestros profundos agradecimientos por la atención que se sirva otorgarle a nuestra solicitud, nos es grato aprovechar esta ocasión para suscribirnos con todo respeto y admiración, sus atentos y servidores que os desean todo bien. $\left(5^{\circ}\right.$ y $6^{\circ}$ año) [firmado].

[Escrito a mano] faltan 90 firmas que pertenecen a los alumnos de $1^{\circ}$ y $2^{\circ}$ grados, pero no lo hacen por no saber escribir con tinta todavía. Los suscritos. $^{18}$

Algunas características de esa solicitud infantil se destacan no obstante su sencillez. En primer lugar, los niños revelan una creencia en el poder de las masas, agregando a sus múltiples firmas el peso de las multitudes de niños invisibles de los primeros grados de la primaria, que aunque no sepan escribir con tinta, merecen el mismo tratamiento y representación que sus colegas mayores. Con esa inclusión, hacen una referencia velada a la supuesta democratización nacional y la inclusión de los menospreciados, los marginados históricamente. En este caso, es la edad, y no la raza ni el género, la que define el acceso al gobierno. En segundo lugar, estos niños hacen una (no muy) sutil referencia a la falta de la Revolución de proveer a todos los pobres con trabajos sugieren que, por el bien de la patria, ésta es una situación que hay que remediar. Utilizando su condición de niños como palanca con el presidente "que ama a la juventud", los niños firmantes le dan un toque personal cuando hacen referencia a la felicidad de su "honorable esposa e hijitos". En tercer lugar, el tono de la carta les disculpa a los niños de ser agresivos en sus "demandas" al presidente; advierten que lo que les fortaleció fue la confianza de que el gobierno priorizaba a la nińez, un valor reforzado por la escuela revolucionaria. En total, el lenguaje y el tono que emplean los niños escritores demuestran un

${ }^{18}$ Carta de Alumnos y Alumnas de la Escuela Oficial Mixta "Emilio Carranza," Sierra Mojada, Coahuila, a Abelardo Rodríguez, 1 de diciembre de 1932, en AGN, fondo Rodríguez, expediente 330/165, Tamaulipas, Coahuila, Baja California. 
entendimiento bastante sofisticado de la creciente cultura burocrática de hacerse escuchar en el ámbito político.

El mimetismo de los procesos políticos adultos no se limitó a las cartas escritas a los funcionarios del gobierno. En algunos casos y, en especial, después de la inauguración de la escuela socialista con su énfasis en la educación de la niñez proletaria, los niños aparecieron como seres políticos en la vista pública. Sus voces se grabaron en la prensa diaria local, nacional e, a veces, internacional. Impulsados por el apoyo de la escuela y el gobierno, los nińos participaron entusiasmadamente en manifestaciones públicas sobre asuntos sociales, sobre todo en campañas antialcohólicas y de higiene. ${ }^{19}$ Un evento en particular llamó la atención de la nación, en vísperas del muy anticipado VII Congreso Panamericano del Niño en 1935, con sede en el Distrito Federal. Se trata del Primer Congreso del Niño Proletario, una reunión de niños y niñas delegados de las escuelas de la capital y sus alrededores designadas las más "típicas" de la población "proletaria" de la nación. Otorgados con una identidad social que conllevaba bastante peso político, los niños proletarios expusieron ponencias en varias sesiones en el transcurso de un par de semanas, durante las cuales expresaron su voluntad política en nombre de sus compańeros escolares. La llegada a México durante el mes de marzo de cientos de delegados internacionales para el VII Congreso dio prestigio a la conferencia infantil y aseguró la presencia de la prensa nacional en sus procedimientos.

Las voces de los nińos resonaban en la esfera pública con tonos familiares a la retórica socialista característica de la gente mayor. Un periodista de El Nacional recopiló las opiniones de varios niños congresistas sobre el Congreso. El niño José Joaquín Girón, del Centro Escolar "Estado de Sonora”, emitió sus críticas de los que solían suprimir la escuela socialista: "Con frecuencia hemos escuchado palabras desorientadoras y críticas mal intencionadas de parte de los elementos contrarios al avance de las masas trabajadoras, elementos

\footnotetext{
${ }^{19}$ Gretchen Kristine Pierce, "Fighting Bacteria, the Bible, and the Bottle: Projects to create New Men, Women, and Children, 1910-1940", en William H. Beezley, ed., A Companion to Mexican History and Culture, Malden, MA, Wiley-Blackwell, 2011, 503517. También véase Loyo B., "En el aula...”, 2006.
} 
que están al servicio del capitalista, pero no nos interesa, ya que los nińos proletarios tenemos confianza en nosotros mismos y en las autoridades que rigen los destinos de nuestra patria” ${ }^{20}$ Claramente, este niño aprendió a utilizar la retórica para expresar una ideología determinada y levantar una crítica clasista de la opresión sufrida históricamente por su comunidad y sus antecedentes. Las palabras de José Joaquín son una representación del primer nivel de aprendizaje: la imitación del discurso de las autoridades. Sin embargo, no todos los niños congresistas encarnaban en cuerpos chiquitos las palabras de los mayores. El compañero de José Joaquín, Luis Rodríguez $\mathrm{H}$., estudiante del $5^{\circ}$ ańo, demostró una actitud matizada hacia las nuevas enseñanzas que recibía, evidente en su vocabulario y en su referencia a la estrecha relación entre el maestro y sus estudiantes en el aula. En su breve discurso hace referencia al proceso de socialización que estaba teniendo lugar en las escuelas socialistas. Según Luis:

El Congreso del Niño Proletario es en mi concepto a base de la expresión concreta y categórica, dentro de un ambiente de completa libertad, para los niños humildes. Esperamos que las ponencias aprobadas en el seno del Congreso se realicen ampliamente, porque confiamos que se establezcan más escuelas, resolviéndose así el grave problema de los escolares que no tienen cabida en las aulas. Si el Congreso alcanza todos sus triunfos se mejorará la situación de los padres de familia y como consecuencia la nuestra. Si los padres no convencidos de las ventajas de la educación socialista, lo dudan, pueden ir a las clases para que se den cuenta de la forma como estamos siendo orientados por nuestros maestros. ${ }^{21}$

Luis se situó en una posición mediadora entre los padres (símbolos de un pasado tradicional e intransigente) y los maestros (mesías del presente moderno y progresista). Sin embargo, sus palabras, publicadas en el diario nacional a la vista de toda la República, revelan una mezcla de las sofisticadas ideas pedagógicas que regían la instrucción

20 "Lo que dicen los niños", El Nacional, 18 de marzo de 1935.

21 "Lo que dicen los nińos", El Nacional, 18 de marzo de 1935. 
de la escuela socialista, y las ideas sencillas y prácticas de lo que se podía mejorar en la vida diaria escolar desde la perspectiva de un niño.

Además, aunque indudablemente los maestros y administradores de la SEP guiaban las acciones y palabras de los niños congresistas, las experiencias vividas por los niños durante el Congreso permanecían tras su vuelta a la escuela. No sólo habían saboreado la valorización pública de sus ideas y acciones, sino también regresaban a sus escuelas como pequeños héroes, reconocidos embajadores oficiales de una institución nacional. En las palabras de la congresista María Ortiz, del Centro Escolar "Domingo Sarmiento", el Congreso:

dejó en mis compañeros y en mí misma magníficas enseñanzas y experiencias, por eso todos los escolares deseamos que pronto se lleve a cabo otro congreso con delegaciones de todas las escuelas del Distrito Federal, para que el contingente sea mayor y el entusiasmo que despierte entre todos sea más poderoso, así como se escuche en forma más amplia la voz de los niños humildes. ${ }^{22}$

Estos niños delegados funcionaban como modelos a seguir para sus compańeros; aunque reconocemos que estas palabras fueron moldeadas, hasta cierto grado, por la influencia de los adultos, para sus coetáneos, estas palabras infantiles publicadas en los diarios nacionales les señalaron que el niño podía -y debía- tener una voz política.

\section{NIÑOS RECEPTORES: CORRESPONDENCIA RELATIVA}

\section{A LOS PROGRAMAS CULTURALES DE LA SEP}

En los años 1930, el currículo extraescolar de la SEP ganó gran impulso entre los niños destinatarios. Entre las variadas iniciativas, los niños tuvieron la oportunidad de responder a dos: la programación infantil transmitida por la estación de radio XFX de la SEP y el teatro itinerante de títeres conocido como el Teatro Guiñol. Las dos iniciativas tenían como objetivo la introducción de una cultura monolítica nacional a la generación más joven a través de novedosas formas

22 “Lo que dicen los niños", El Nacional, 18 de marzo de 1935. 
de entretenimiento y educación. A través de las ondas de la radio o las muñecas articuladas, estos programas exponían a los niños fuera de la capital a los valores, las normas, la historia, las canciones y la cultura popular de la nación, una invención en proceso que apenas empezaba a acumular los símbolos de su identidad.

La naturaleza de estas iniciativas educativas alentó la participación discursiva de los niños del público. A partir de su correspondencia, nos damos cuenta de que algunos nińos cuestionaban los procesos democráticos y la verdadera representación del pueblo en los proyectos del Estado (aunque indiscutiblemente la gran mayoría de estos niños simplemente reflejaban esas injusticias políticas desde su estrecha visión definida por el contexto familiar o escolar). Además, sus cartas revelan detalles y pistas de sus vidas cotidianas. Sobre todo, estos niños afirmaban que su estado social de niño o niña no los limitaba, producto de casi una década de retórica oficial que elevaba el niño como el recurso más precioso de la nación. Una serie de cartas al director del programa de radio llamado Periódico infantil, de la mencionada estación XFX, contiene evidencia de que los niños se sentían con el derecho de participar en los concursos que ofrecía el programa y ganar premios democráticamente, por pobres o enfermos o chiquitos que fueran. Por ejemplo, en 1930 el pequeño Gabriel Salazar escribió como concursante en una de las pruebas semanales:

Respetable Sr., Siendo yo uno de los colaboradores de "Periódico Infantil" le envio a Ud por estas lineas, para decirle que aún cuando radio escucha de Periódico Infantil soy un nińo pobre, y que si Ud cree que sea conbeniente que hastistir a la fiesta nińos pobres como lo soy yo estoy en las mejores condiciones para solisitar la imbitación que Ud ofreció para la fiesta de repartición de premios. Si Ud me cree digno de su amable imbitación, la antisipo las mas escpresibas gracias. ${ }^{23}$

23 “Reportes de Periódico Infantil", Archivo Histórico de la Secretaría de Educación Pública (AHSEP), fondo Oficina Cultural Radiotelefónica (OCR), caja 9475, expediente 14, 1930. 
Incluyó su dirección y su firma. Por las faltas de ortografía, podemos asumir que a la carta de Gabriel no fue intervenida por la mano de ningún adulto educado y que las palabras reflejan una sincera expresión suya. Además, su tono sumiso indica una humildad hacia las autoridades quizás aprendida al observar semejantes expresiones en las interacciones burocráticas de los adultos en su ámbito, una característica de su escritura que refleja el proceso por el que los niños absorbían mensajes implícitos sobre su relativa posición en el orden social. Utiliza un lenguaje que se aproxima al oficial, lo que sugiere que había escuchado a los adultos en similares transacciones o peticiones con sus superiores y que conoce la importancia de escribir para que le den solución a su petición. Lo más poderoso de esta sencilla carta es el reconocimiento del pequeño autor de su estado socioeconómico relativo a los demás niños que escuchaban el Periódico infantil radial; a través de su correspondencia, Gabriel reclama que los niños pobres también tienen derecho a participar en los eventos culturales patrocinados por el gobierno. Dentro de sus humildes líneas, Gabriel reconoce la posibilidad de una nueva democratización dada la nueva tecnología de la radio.

Otro niño, Luis Becerril, cuestionó las posibles injusticias dentro del sistema establecido por el Periódico infantil que requería que los niños entregaran diariamente por correo sus respuestas a las preguntas. En una carta bastante filosófica, Luis escribe:

¿Quién creo que sea digno del premio? ¿El que las reporta a diario o el que las reporta cada tres días? Señor, el que las reporta todo los días lo hace porque en su casa cuentan con más dinero, y en la mía es escaso, aunque es una insignificancia los seis centavos, hay días que no los tiene mi mamá, por eso junto tres notas para mandárselas juntas. ${ }^{24}$

La carta del joven abogado Luis demostró aquí una conciencia de quién era su público y se aprovechó de la oportunidad de presentar su caso como un argumento para la justicia social. Su meta fue la parti-

24 “Concurso Periódico Infantil”, AHSEP, OCR, caja 9476, expediente 45, folio 468, 1930. 
cipación de todos en un programa diseñado por la SEP precisamente con este propósito: un programa infantil de radio que llegara hasta a los pueblos más retirados, y hasta los oídos de los analfabetos, para complementar la educación gratuita y obligatoria que prometió el artículo $3^{\circ}$ de la Constitución de 1917. Luis se apoyó en su narrativa íntima de la economía particular del niño promedio para resaltar las posibles injusticias integradas en la estructura de los concursos diarios del Periódico infantil. Aunque su pedido parezca incidental, la carta de Luis demuestra una capacidad de cuestionamiento de la transparencia de las funciones del gobierno en un aspecto que afectó su vida como niño y fue una observación astuta que pudo haberse aplicado a muchas instituciones estatales en todos los niveles del gobierno.

En un análisis de documentos infantiles, hay momentos en que se ve claramente hasta qué punto los padres y otros adultos intervenían los documentos escritos por los niños. Pero estos gestos editoriales permiten al historiador utilizarlos como un lente por el que se observan las vidas cotidianas de los niños, de una forma que no la capturan las instituciones que rigen sus vidas en la esfera pública. Por ejemplo, otra concursante del Periódico infantil, la niña Ana María Saldaña, explicó su respuesta a la pregunta de cómo funciona el aparato de radio y agrega como parte de su narrativa, de una forma espontánea y genial, algunos detalles de su vida familiar:

Muy señor mío: Contesto a su pregunta de 'cómo funciona un radio receptor,' naturalmente yo he tenido que preguntarlo pues aunque en mi casa he visto y tenido varios y muy diferentes, dados mis pocos años no he podido ni puedo aun darme cuenta.

Si esto no lo permiten Uds. tendre que renunciar a la esperanza de un premio de los ciento y pico que Uds. ofrecen.

Según lo que he podido entender de las explicaciones que me a dado mi papá el aparato de mi casa es un regenerativo simple, tan simple que yo misma lo he manejado muchas veces. Tiene un condensador y una inductancia variable que me dijeron es el sintonazidor.

[...] He dicho todo lo que se de radio y creo que mi papá que es el que me ha contado todo esto tampoco sabe mas, él no ha querido ver lo que escribo pues dice que si pongo un disparate perdere el premio, pero creo es por 
que no puede corregirme. Con gusto recibire, si me ago acredora, lo que Uds. me manden me gustan mucho los cuentos y las muñecas mas.

Espero que me perdonen el haber escrito con lapiz pero mi papá no quiere prestarme su pluma porque dice que no la se usar y se la rompa.

Quedo a sus ordenes en Pino Suarez 59 interior 9.

Ana María Saldaña

P.D. la carta me la corregio la Chata por que dice que lo hago muy mal, pero eso no es cierto. ${ }^{25}$

Por medio de lo que es, a primera mirada, un gracioso relato infantil, Ana María nos brinda algunas pistas sobre su vida. Queda claro, por su testimonio, que la nińa redactó la carta sin el apoyo de los adultos que vivían en su casa. Sus palabras son reveladoras cuando describe las relaciones diarias que tiene con su padre y con "la Chata”, que posiblemente era la ayudante doméstica. En primer lugar, consultó a su padre en cuanto a una duda sobre tecnología, subrayando la asociación masculina con los aparatos electrónicos. En segundo lugar, el apodo peyorativo y la arrogancia (que también se podría leer como autoconfianza) con que trata a "la Chata" sugieren que la niña es la que tiene la última palabra. Detalles mundanos (que su papá no le quiso prestar su preciosa pluma, que ha tenido varios aparatos de radio en su casa, el papel cotidiano de "la Chata") pintan el panorama de una parte del público infantil del Periódico infantily desmienten la aserción de los oficiales educativos de que el mayor propósito de la educación por radio fuera para hacerle llegar a los pueblos lejanos el mensaje revolucionario. ${ }^{26}$ Como la gran ma-

25 “Concurso Periódico Infantil”, AHSEP, OCR, caja 9476, expediente 45, folio 525, 1930.

${ }^{26}$ El uso de la radio como solución a la escasez de maestros rurales se dio a conocer a partir de 1924, con la fundación de la XFx encabezada por María Luisa Ross. Funcionarios de la SEP llevaron aparatos a localidades retiradas que quedaban dentro del rango de los emisores de la XFX, como suplementos o sustitutos de la escuela. No obstante, los obvios problemas de recepción, en pocos años los aparatos de radio aparecieron en las zonas rurales durante las décadas de 1920 hasta 1940, en anticipación de la llegada de las prometidas escuelas. Véase Joy Elizabeth Hayes, Radio Nation: Communication, Popular Culture, and Nationalism in Mexico, 1920-1950, Tucson, University of Arizona Press, 2000; y Roberto Ornelas Herrera, "Radio y cotidianidad en México (1900-1930)”, Pilar 
yoría de los que escribían cartas al programa de XFX, Ana María disfrutaba de una vida acomodada y urbana, y la tecnología de la radio no era para ella tan novedosa. No obstante, la retórica oficial educativa que alabó la programación de la estación XFX como la solución a la falta de recursos para las escuelas rurales (Periódico infantil fue visto por sus creadores como un ramo de la SEP que extendía a los pueblos lejanos la pedagogía moderna), ${ }^{27}$ la carta de Ana María representa el público infantil ideal: uno dotado de tiempo libre, $\mathrm{cu}-$ riosidad, adultos consejeros (por distanciados que fueran) y con acceso a la tecnología.

La escasez de cartas de los niños pobres no quiere decir que no escucharon la programación; vistas las dificultades que experimentaba Ana María desde su privilegiada posición, podemos imaginar lo que confrontaban los nińos pobres en los pueblos remotos al querer participar en un concurso por radio: conseguir papel y lápiz; escribir la tarea; contar con alguien que se las corrigiera; comprar una estampilla y un sobre; y acudir a la oficina de correos, todo eso; y además cumplir con los quehaceres domésticos, le hacía casi imposible a un niño rural participar a la par con un compatriota urbano, educado y con recursos.

Otra iniciativa cultural promulgada por la SEP, con fines de inculcar en la generación heredada de la Revolución un amor a esa patria abstracta, fue la enseñanza del dibujo nacional. Existe la tendencia de considerar al dibujo infantil como un simple pasatiempo, a lo sumo una bonita decoración y no algo meritorio del análisis histórico. Sin embargo, en los años 1920 y 1930, los oficiales de la SEP se dieron cuenta de que el dibujo representaba una herramienta didáctica para unir el juego y la enseñanza en las aulas de clase. La Sección de Dibujo y Trabajos Manuales de la SEP, bajo la dirección del artista y autor Adolfo Best Maugard, proclamó el dibujo como área de estudio obligatorio dentro del currículo de la es-

Gonzalbo Aizpuru, dir., Aurelio de los Reyes, coord., Historia de la vida cotidiana en México. Siglo XX. Campo y ciudad, tomo v, vol. 1, México, El Colegio de México, Fondo de Cultura Económica, 2006, 127-169.

${ }^{27}$ Boletines de Acercamiento entre el Hogar y la Escuela, AHSEP, OCR, caja 9485, expediente 49, 1933. 
cuela primaria, con las metas de enseñar a los niños a cultivar la sensibilidad estética, apreciar las tradiciones artísticas nacionales, expresar sus ideas y embellecer el hogar, la escuela y la comunidad. Para lograr el éxito en su programa de arte, los maestros basaron sus enseñanzas en la observación del medioambiente regional. Continuas visitas de los inspectores escolares aseguraron que se desarrollara en una forma sistemática por todo el país. ${ }^{28}$

Los dibujos producidos por los nińos en esta época se reprodujeron en revistas y otras publicaciones de la SEP; se imprimieron en carteles de propaganda para la educación socialista; se usaron en las campañas antialcohólicas; y algunos fueron guardados en los archivos de la SEP para la consideración de los funcionarios educativos. Como señalé en la introducción, hubo exposiciones en espacios públicos (como el muy transitado patio de la SEP), que llevaron estas obras infantiles a la vista del pueblo. Además, algunos profesores reclutaron a sus estudiantes para decorar las aulas y los muros exteriores de los edificios escolares con diseños de su propia invención. ${ }^{29}$ Por ejemplo, una foto muestra a cuatro niñas de la Escuela núm. 66 en la ciudad de México en el proceso de pintar su aula, lo que dejaría una impresión visual semipermanente. Esta foto, publicada en una revista estadounidense, llamó la atención de una reportera de la Cruz Roja por ser para ella el caso mexicano un fenómeno tan único. Reconocemos que la forma y el contenido de muchos de estos dibujos fueron fuertemente guiados por la mano de un adulto, especialmente los que se crearon dentro del ambiente escolar. Sin embargo, representan la expresión artística de los niños como la única evidencia de esta época histórica; casi todos los niños aprenden a dibujar antes de que aprendan a expresarse con la palabra escrita. Los dibujos son textos visuales que se leen igual que cualquier otro documento.

El vehículo más efectivo para colocar los dibujos infantiles en la esfera pública fue la publicación Pulgarcito, la anteriormente mencionada revista con mayor contenido infantil publicada y distribui-

28 "Dictámenes sobre Enseñanza de Dibujo", AHSEP, fondo Departamento de Bellas Artes, serie Dibujo 1923-1933, caja 23, expediente 1, 1931.

${ }^{29}$ Emma Reh Stevenson, "Mexico's Story in Color", High School Service (órgano de The American National Red Cross), vol. v, núm. 1, septiembre de 1928, s/p. 


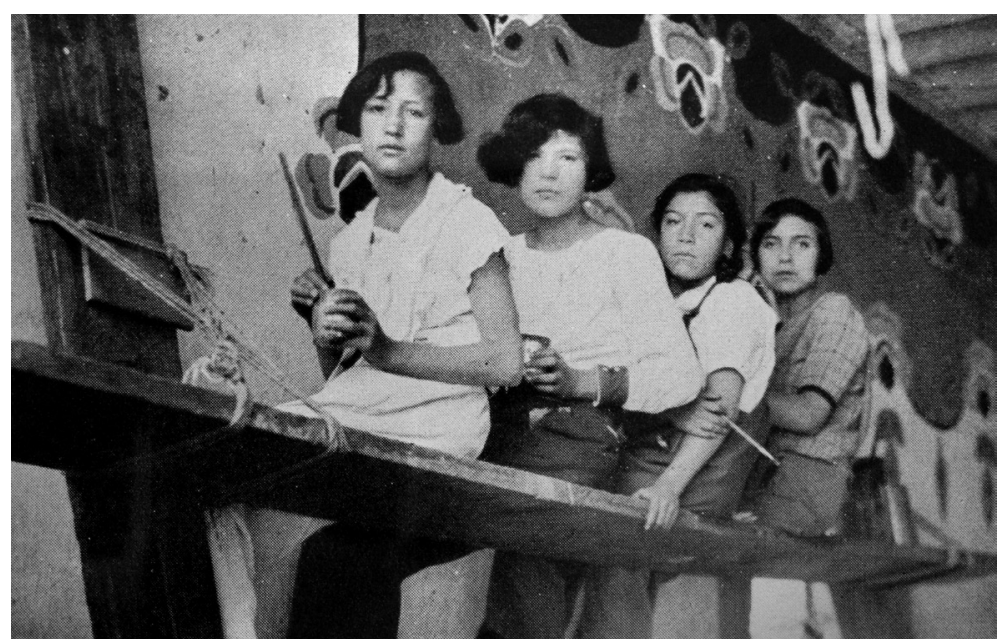

Documento 1. Nińas pintando las paredes de su aula. Emma Reh Stevenson, "Mexico's Story in Color", High School Service (órgano de The American National Red Cross], vol. v, núm. 1, septiembre de 1928, s/p.

da gratis por la SEP entre 1925 y 1932 bajo la dirección del escultor Juan Olaguíbel, reconocido por su escultura Diana la Cazadora sobre la Avenida Reforma, entre otras piezas. Adolfo Best Maugard promovió un estilo de dibujo basado en los elementos más básicos que observó en el arte y la arquitectura de las culturas prehispánicas de Mesoamérica. Según su Método de dibujo, publicado en 1924, cualquier estudiante de arte sería capaz de producir imágenes distinguidamente mexicanas con la incorporación de estos detalles. ${ }^{30} \mathrm{Pul}$ garcito sólo publicó los mejores (o más nacionalistas) resultados de los millares de dibujos y cuentos entregados por los niños. Aunque se desconoce el proceso de selección, en la última página de cada número de la revista había una sección llamada "Buzón de Pulgarcito", en la que los editores regańaban a los niños que no se sujetaban a las normas (de estilo técnico o contenido). Por eso se podría decir

${ }^{30}$ Adolfo Best Maugard, Método de dibujo: tradición, resurgimiento y evolución del arte mexicano, 2a edición, Mexico, Editorial Viñeta, 1964; Fernando Best Pontones, "El método "Best Maugard" para la enseñanza del dibujo, y su aplicación a los trabajos manuales”, Boletín de la SEP, tomo I, núm. 2, 1922. 
que los dibujos hechos por niños que aparecen en las páginas de Pulgarcito -e incluso los textos que los acompañan-sufrieron una sobreinstrucción, fuertemente guiados por el currículo de Best Maugard y seguramente revisados por los maestros en las clases de arte. Sin embargo, algunas estrategias escogidas por los niños demuestran una conciencia sobre su etnia, su estado socioeconómico y su propio público de niños lectores.

La mayoría de los niños que contribuyeron a la publicación de Pulgarcito eran de la capital. Los dibujos de los niños de los estados se demoraban más en llegar a las oficinas de la SEP y muchas veces no alcanzaban las fechas límites para cada edición. Además, la revista creó espacios físicos (como las oficinas de la SEP, o el Teatro Hidalgo, por ejemplo) para que los niños dibujantes interactuaran entre ellos a través de festivales, fiestas de cumpleańos y otras reuniones infantiles. Obviamente, los niños de los estados no podían asistir a estas reuniones, lo que reforzaba la jerarquía entre los niños capitalinos y sus compatriotas en las afueras. Sin embargo, la revista Pulgarcito sí llegaba a las provincias y los pequeños colaboradores entregaron obras y textos que mostraron una conciencia de cómo negociar las percepciones -romantizadas e indigenistas- del "México profundo" en donde vivían. Por ejemplo, una niña, María del Carmen Talavera de Pátzcuaro, Michoacán, publicó el dibujo y el cuento de su visita a la isla de Janitzio, un pueblo indígena a unos minutos en lancha del pueblo no mucho más urbano de Pátzcuaro. El dibujo que hizo María del Carmen de la isla está repleto de las requeridas flores y bellezas asociadas con el "paisaje auténtico" de los indígenas, siguiendo las reglas estipuladas por Best Maugard en su Método de dibujo. Además, en su descripción, María del Carmen emplea un tono antropológico que hace de los objetos de su visita unos seres exóticos, primitivos, auténticos y, sobre todo, muy nacionales. Se emocionó cuando "los inditos" les invitaban a comer después de haber presentado un baile folklórico. Sin embargo, cuando truenan los cielos y empiezan a gotear, María del Carmen expresa la desesperación con la que ella y sus compañeros de clase corren a las lanchas para volver a Pátzcuaro. En una sola frase de su escritura, el lector puede seguir la trayectoria entre las oposiciones binarias de la isla 


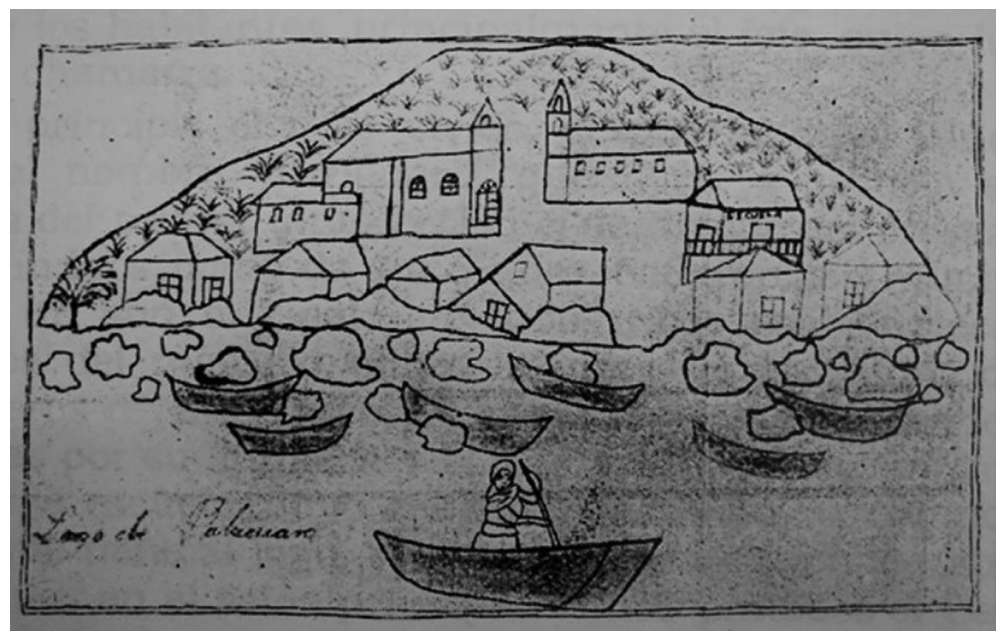

Documento 2. Isla de Janitzio, Lago de Pátzcuaro, por la nińa María del Carmen Talavera, 5० ańo Pulgarcito, septiembre 1926, 16.

antigua y la ciudad moderna, una distancia corta pero señalada por muchos códigos culturales a la vista de María del Carmen:

como la tempestad se anunciaba y temiendo los peligros del lago, nos embarcamos inmediatamente, $[y]$ las inditas nos llevaron a las canoas las cazuelas de comida y las jícaras con tortillas, y navegando, comimos al arrullo de las olas, desembarcando antes de las cuatro en la Hacienda Ibarra, próxima a la estación del ferrocarril, donde esperamos los tranvías que nos trajeron al centro de la ciudad, dirigiéndonos inmediatamente a nuestra querida escuela. ${ }^{31}$

De canoas a tranvías, María del Carmen y sus compañeros regresaron de su excursión al "otro México" y volvieron a la rutina de su vida moderna. La distancia se percibe más aguda por el hecho de ser Janitzio una isla, rodeada por agua y accesible sólo por una de las vías más antiguas de transporte, una observación hecha explícita en el dibujo que acompańa el ensayo. Implícito en su narrativa (y

${ }^{31}$ Pulgarcito, año II, núm. 17, septiembre de 1926, pp. 16-7. 
subrayado en su dibujo) es el conocimiento de los códigos étnicos con que se habla de lo que se le refería como "la raza indígena". También implícito es el conocimiento de que sus amiguitos invisibles en la capital la puedan considerar como provinciana y, con el sutil uso de la retórica, se distancia de los indígenas pintorescos y hace referencia a su propia urbe de Pátzcuaro.

Otra niña michoacana, Manuela Pimentel, de diez años, publicó un dibujo de un ranchero y su familia, una de las grandes estampas nacionales de la época revolucionaria. ${ }^{32}$ En su dibujo, Manuela enfatizó las características emblemáticas de un ranchero -su sarape estilizado, su sombrero y sus botas-. En su ensayo, habló como se tenía que hablar de los trabajadores del proletariado: de su humildad, su generosidad y su bondad con sus tres hijas: "Las lleva todos los domingos al teatro, porque son muy aplicadas en la escuela y muy obedientes con él y su mamá; los respetan y nunca los hacen disgustar. Imitemos, pues, a esas niñas aplicadas y obedientes, y veremos que nuestro papá ha de imitar también". ${ }^{33}$ Para ser publicada en Pulgarcito, una contribución artística de los estados tenía que mencionar la autenticidad del mundo rural como sede del imaginario nacional, mientras los niños capitalinos se encargaron de dibujar trenes y tecnología, los heraldos de la modernidad. En incontables ocasiones, los editores, en la sección "Buzón de Pulgarcito", reprendían a los niños de Jalisco, Michoacán, Colima y otros estados, por no haber enviado muestras de la belleza natural o el folclor regional de sus respectivos hogares. Una versión esencialista de los dos Méxicos emergió durante la posrevolución, a pesar de que tomó muy poco tiempo reforzar esta imagen en las páginas de Pulgarcito, los niños demostraron un entendimiento básico de sus respectivos lugares (merecidos o no) en la nueva nación, y como miembros jerarquizados -étnica o socioeconómicamente- de una nueva generación.

\footnotetext{
${ }^{32}$ Ricardo Pérez Montfort, Estampas de nacionalismo popular mexicano: diez ensayos sobre cultura popular y nacionalismo, $2^{\mathrm{a}}$ edición, México, Centro de Investigaciones y Estudios Superiores de Antropología Social, 2003 y Avatares del nacionalismo cultural: cinco ensayos, México, Centro de Investigación y Docencia en Humanidades del Estado de Morelos, Centro de Investigaciones y Estudios Superiores de Antropología Social, 2000.

${ }^{33}$ Pulgarcito, año II, núm. 17, septiembre de 1926, 26.
} 


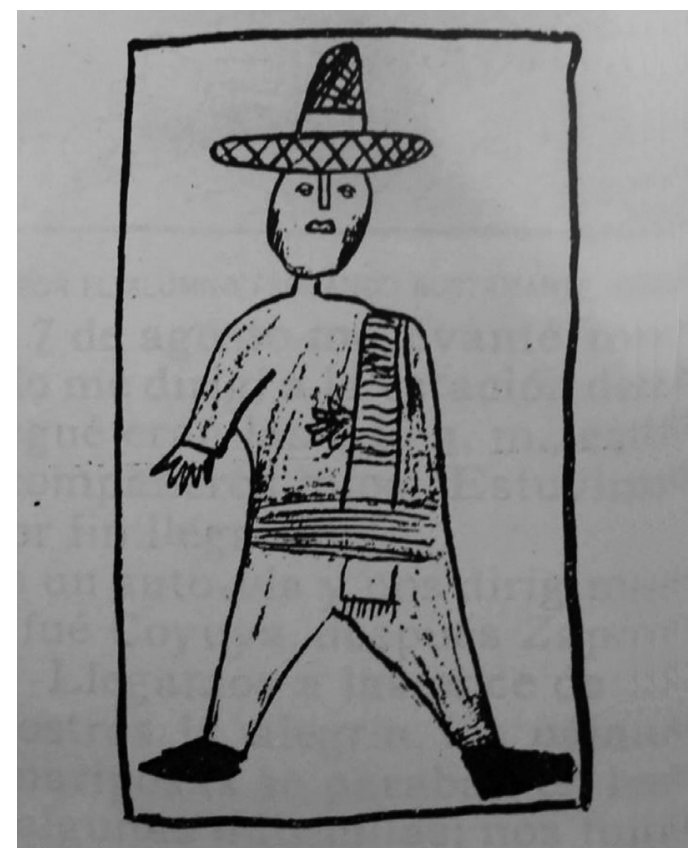

Documento 3. Ranchero, por la niña Manuela Pimentel, edad 10 ańos, Escuela Elemental Federal "Ignacio Altamirano”, Pulgarcito, septiembre, 1926, 26.

Otra iniciativa de la SEP para hacerles llegar a las escuelas rurales los mensajes revolucionarios de higiene, salud, trabajo, patria y moral, tomó forma en el Teatro Guiñol, también conocido como Teatro del Niño, el cual se componía de una tropa de artistas de títeres que viajaban de escuela en escuela. ${ }^{34} \mathrm{El}$ experimento fue concebido como un vehículo para la diseminación y la recepción universal de un aspecto de la cultural infantil. Los niños respondieron a los espectáculos de títeres con dibujos de lo que habían visto. Estos dibujos se mandaron a las oficinas de la Comisión de Repertorio -encargada de censurar el contenido de las obras de teatro- para evaluar si los niños habían

${ }^{34}$ Marisa Giménez Cacho, Hugo Hiriart y Fernando de Ita, El Teatro Guiñol de Bellas Artes: Época de oro, México, RM, Instituto Nacional de Bellas Artes, 2010. 
captado la ideología revolucionaria que intentaban promover los títeres. En muchos casos, debido a diferencias culturales o la falta de madurez de parte de los niños más jóvenes, los oficiales tuvieron que alterar el contenido de los espectáculos porque los niños mostraron evidencia en sus dibujos de que no siempre entendían lo que tenían que aprender y no siempre veían lo que tenían que ver en los títeres.

De hecho, los dibujos indican distintos niveles de sofisticación en la manera en que los diferentes niveles escolares recibieron las obras. Muchas veces, los niños del kínder se fijaron en un solo personaje y se dedicaron a la fiel reproducción de su forma física. Esta observación, tomada junto con las observaciones de los maestros de que los nińos menores se espantaron con los títeres, creyendo que eran seres vivos o monstruos, indica que los niños más chiquitos no pudieron recibir con mayor claridad los mensajes de los títeres porque estaban obsesionados con su presencia física. Para esos niños, el teatro y los títeres formaron un sustituto visual de sus experiencias vividas y lo tomaron como realidad. Por ejemplo, en esta representación dibujada por un niño del kínder, los títeres aparecen en el campo, rodeados por los mismos animales, montańas y árboles que le eran familiares al pequeño artista, pero en el dibujo no se ve ni el público ni una marcada distancia entre la fantasía y la realidad. Este niño artista no distinguió entre los títeres y los animales que poblaron su comunidad. En 1934, después de analizar los dibujos de los niños más jóvenes, junto con las cartas de evaluación de sus maestros, la Comisión del Repertorio decidió agregar otro grupo de titiriteros itinerantes al Teatro Guiñol diseñado específicamente para los niños menores de seis años, con presentaciones más sencillas y con muñecos menos espantosos. ${ }^{35}$

Los niños mayores, sin embargo, pudieron identificar a los títeres como actores manipulados por seres humanos y demostraron un entendimiento de una presentación dramática que se veía en sus dibujos. Estos dibujos incluían más contexto físico, como las sillas y el público y casi siempre enmarcaban la acción en la puesta en escena con la plataforma y las cortinas que formaban parte del escenario ru-

\footnotetext{
${ }^{35}$ AHSEP, fondo Departamento de Bellas Artes, serie Teatro, caja 71, expediente “Teatro del Nin̄o", 1934.
} 


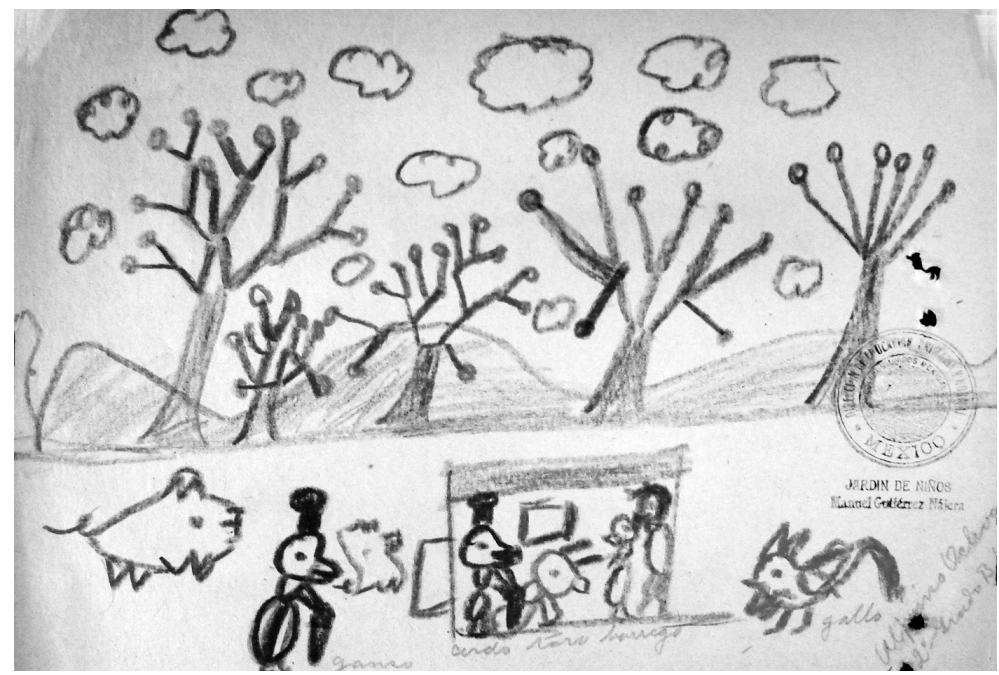

Documento 4. Dibujo del Teatro Guiñol hecho por un niño del kínder. Archivo Histórico de la Secretaría de Educación Pública (AHSEP), Departamento de Bellas Artes, serie Teatro, caja 4949, 1934.

dimentario con que los artistas armaban el Teatro Guińol. Algunos alumnos hasta se incluían a sí mismos en el dibujo como espectadores de la acción, un detalle revelador que demuestra su autoconciencia delante de una representación artística para el público, así como su papel como observador y consumidor de una nueva forma de educación y entretenimiento. Un estudiante del cuarto grado llamado Alfredo se dibujó a sí mismo y sus compañeros de clase, cuidadosamente alineados con la mirada fija en los cuatro títeres a todo color actuando en el escenario. El público ocupa tanto espacio en la hoja como los títeres. El demostrado conocimiento de la escala de espacio, dimensión y relatividad de los sujetos de su arte sugiere que los estudiantes mayores, como Alberto, distinguieron entre la realidad de su presencia y la ficción de las experiencias de los títeres. ${ }^{36}$

${ }^{36}$ Véase el análisis de estos dibujos en Elena Jackson Albarrán, “Comino vence al diablo and Other Terrifying Episodes: Itinerant Children's Puppet Theater in 1930s Mexico", The Americas, vol. 67, núm. 3, enero 2011, 355-374. 


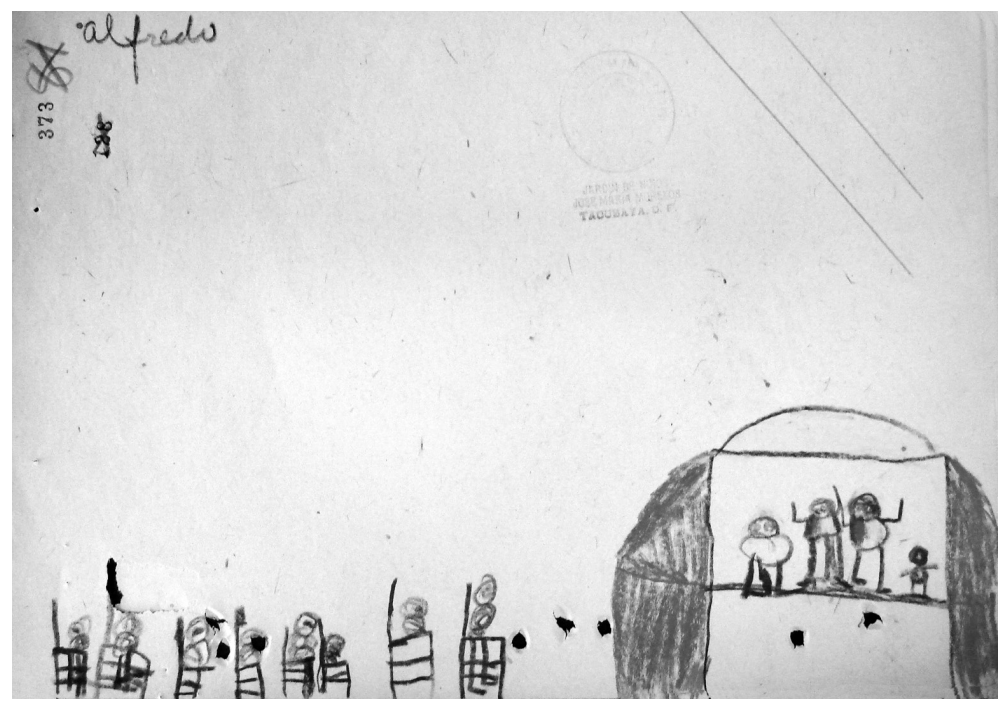

Documento 5. Dibujo del Teatro Guiñol hecho por un niño mayor. AHSEP, Departamento de Bellas Artes, serie Teatro, caja 4949, 1934.

Otra característica de los dibujos que los niños pintaron después de ver el espectáculo del Teatro Guiñol fue la dominante presencia del Diablo. Apareció en muchas obras de los títeres como metáfora para la clase opresora, el patrón aprovechador, la burguesía o cualquiera de los varios males sociales que los niños aprendían a rechazar. Pero como el Teatro Guiñol representó la ideología de la educación socialista, no fue la intención de los artistas de títeres hacer referencias religiosas. Sin embargo, no tomaron en cuenta que para el público infantil en los lugares rurales, el Diablo ocupaba una notada presencia en la iconografía popular (algo que persistía a pesar de los esfuerzos del gobierno revolucionario de secularizar la nación), representaba para ellos una verdadera amenaza en sus vidas diarias, mucho más que los conceptos abstractos como la explotación del proletario. Su obsesión con el Diablo limitó su habilidad de interpretar su presencia simbólica en las obras de los títeres y esto está confirmado en sus dibujos. La mayoría de las presentaciones del Teatro Guiñol consistían en tres cortas obras, casi siempre incluían 
al muy popular Comino vence al Diablo escrito por Germán List Arzubide. A pesar de que presentaban tres obras, la gran mayoría de los niños dibujaban escenas de Comino vence al Diablo, más impresionante aún fue la desproporcionada apariencia del Diablo en sus dibujos. Es más, gran mayoría de los niños dibujaban la escena de la obra en donde Comino y el Negrito golpean al Diablo (quien realmente es el patrón disfrazado del Diablo); esto sugiere que los nińos interpretaron que la moraleja de la obra estaba basada en la violencia como solución a la injusticia social, perdiéndose el mensaje sobre la necesidad de vencer la explotación del trabajador. Las cartas de los maestros confirmaban que los niños se quedaban con la preocupación de por qué el Diablo aparecía en las obras, haciendo repetidas preguntas como, “¿Es cierto que el Diablo existe? Mi mamá dice que los ángeles hacen desaparecer al Diablo. Nadie le puede pegar al Diablo sino los ángeles”. Una maestra escribió a la SEP diciendo que, como maestra socialista, no esperaba tratar asuntos teológicos y que el contenido de las obras le traía más confusión a sus estudiantes que respuestas. ${ }^{37}$ La Comisión de Repertorio respondió y mandó sustituir al Diablo por otro personaje con menos resonancia cultural para que no se perdiera el sentido revolucionario en medio de confusiones religiosas. ${ }^{38}$

Dibujos como estos llenan nuestro entendimiento histórico del proyecto concentrado de la SEP de llevar su misión educativa a las escuelas rurales, porque agregan la perspectiva de la población de niños destinatarios de las reformas revolucionarias. En este caso, los dibujos son mucho más que caprichos infantiles; señalan la distancia que puede haber entre los intereses del Estado y la recepción por parte de los niños. Las caricaturas rudimentarias conllevan significados profundos del impacto que tienen factores como la edad, la religión y la etnicidad en la recepción infantil de un proyecto cultural conceptualizado por adultos.

${ }^{37}$ AHSEP, fondo Departamento de Bellas Artes, serie Teatro, 1932-1936, caja 71, expediente 43.

${ }^{38}$ AHSEP, fondo Departamento de Bellas Artes, serie Teatro 1932-1936, caja 71, expediente "Teatro del Niño", 1934. 


\section{Conclusiones}

Cartas, dibujos y testimonios infantiles como los aquí revisados han sido considerados como poco importantes para ser guardados. Sin embargo, en algunos archivos históricos y, sobre todo, en los que contienen la vasta colección de material proveniente de la época de expansión y experimentación educativa, ¿existe material que nos acerca a la voz infantil que se enraíza en la historia? Una cuidadosa lectura de estos documentos contribuye a la reconstrucción de una historia cultural de la infancia posrevolucionaria. Los documentos no son perfectos; seguramente han sufrido ediciones, manipulaciones, revisiones u omisiones que dejan huecos en esta historia que queremos recuperar. Es más, como indican algunos datos mostrados aquí, algunos documentos eran seleccionados para su publicación, difusión y mantenimiento en los archivos de acuerdo con los criterios y prejuicios de los adultos. Muchos historiadores investigan los proyectos oficiales con el fin de mejorar la población infantil, pero muy pocos toman en cuenta la recepción de esos proyectos por parte de los nińos. Aunque debemos reconocer los desafíos de basar nuestro análisis en los rastros históricos dejados por los nińos, ésta es una invitación para rescatar y trabajar con los pocos documentos que hay. Estas fuentes confirman que la generación revolucionaria estaba interactuando con los textos, la retórica, la ideología y las imágenes promulgados por la SEP y resuenan el espíritu del llamado Grito de Guadalajara de Plutarco Elías Calles para priorizar la integración de los niños en el proyecto revolucionario. Algunos textos infantiles nos muestran que hay un desequilibrio entre las experiencias de los niños de diferentes clases socioeconómicas. Pero a la vez dan cuenta de que existe una experiencia común compartida entre ellos aunque no se conocieran físicamente. La interpretación del niño depende de su momento histórico, su lecho familiar y su contexto cultural, y resulta que su perspectiva puede ser tan efímera como las huellas que deja en la historia. Las valiosas fuentes producidas por los nińos son una ventana a sus pensamientos, olvidados tal vez hasta por ellos mismos ya en sus avanzados años. 
FuENTES Y BIBLIOGRAFÍA

Archivos

Archivo General de la Nación (AGN)

Fondo Obregón-Calles

Fondo Rodríguez

Archivo Histórico de la Secretaría de Educación Pública (AHSEP)

Fondo Oficina Cultural Radiotelefónica (OCR)

Fondo Departamento de Bellas Artes

Hemerografía

High School Service, 1928

El Nacional, 1935

Pulgarcito, 1926-1931

BiBLIOGRAFÍA

Albarrán, Elena Jackson, "Comino vence al diablo and Other Terrifying Episodes: Itinerant Children's Puppet Theater in 1930s Mexico", The Americas, vol. 67, núm. 3, enero 2011, 355-374.

Best Maugard, Adolfo, Método de dibujo: tradición, resurgimiento y evolución del arte mexicano, 2a edición, México, Editorial Viñeta, 1964.

Best Pontones, Fernando, “El método 'Best Maugard' para la enseñanza del dibujo, y su aplicación a los trabajos manuales", Boletín de la SEP, tomo I, núm. 2, 1922.

BuIss, Katherine Elaine y Ann S. Buum, "Dangerous Driving: Adolescence, Sex, and the Gendered Experience of Public Space in Mexico City", en William E. French y Katherine Elaine Bliss, eds., Gender, Sexuality, and Power in Latin America since Independence, Lanham, Rowman \& Littlefield Publishers, Inc., 2007, 165-166. Buum, Ann Shelby, Domestic Economies: Family, Work and Welfare in Mexico City, 1884-1943, Lincoln, University of Nebraska Press, 2010. 
, "Breaking and Making Families: Adoption and Public Welfare, Mexico City, 1938-1942”, Jocelyn Olcott, Mary Kay Vaughan, Gabriela Cano, eds., Sex in Revolution: Gender, Politics and Power in Modern Mexico, Durham, Duke University Press, 2006, 127-146.

Cohen, Daniel A., "Rewriting The Token of Love: Sentimentalists, Sophisticates, and the Transformation of American Girlhood, 1862-1940", Journal of the History of Childhood and Youth, vol. 4, núm. 2, primavera 2011, 223-256.

Fell, Claude, José Vasconcelos: los años del águila. Educación, cultura e iberoamericanismo en el México postrevolucionario, Serie de historia moderna y contemporánea 21, México, Universidad Nacional Autónoma de México, 1989.

Gallo, Rubén, Mexican Modernity: The Avant-Garde and the Technological Revolution, Cambridge y Londres, The MIT Press, 2005.

Giménez Cacho, Marisa, Hugo Hiriart y Fernando de Ita, $E l$ Teatro Guiñol de Bellas Artes: Época de oro, México, RM, Instituto Nacional de Bellas Artes, 2010.

HaYes, Joy Elizabeth, Radio Nation: Communication, Popular Culture, and Nationalism in Mexico, 1920-1950, Tucson, University of Arizona Press, 2000.

KLIne, Stephen, "The Making of Children's Culture", The Children's Culture Reader, ed., Henry Jenkins, Nueva York, New York University Press, 1998, 95-109.

Loyo Bravo, Engracia, "En el aula y la parcela: vida escolar en el medio rural (1921-1940), Aurelio de los Reyes, ed., Historia de la vida cotidiana en México. Siglo XX. Campo y ciudad, tomo v, vol. 1, México, El Colegio de México, Fondo de Cultura Económica, 2006, 273-312.

Loyo Bravo, Engracia, Cecilia Greaves y Valentina Torres, Los maestros y la cultura nacional, 1920-1950, 5 tomos, México, Museo Nacional de Culturas Populares, SEP, 1987.

MacGregor, Josefina, México de su puño y letra: el sentir de un pueblo en las cartas al presidente, México, Editorial Diana, 1993.

Marshall, Dominique, "Children's Rights and Children's Action in International Relief and Domestic Welfare: The Work of Her- 
bert Hoover between 1914 and 1950", Journal of the History of Childhood and Youth, vol. 1, núm. 3, otoño 2008, 351-388.

Meneses Morales, Ernesto, Tendencias educativas oficiales en México, 1911-1934. La problemática de la educación mexicana durante la Revolución y en los primeros lustros de la época posrevolucionaria, México, Centro de Estudios Educativos, Instituto Iberoamericano, 1998.

Nava Nava, María del Carmen, Los abajo firmantes: cartas a los presidentes, México, SEP, Unidad de Publicaciones Educativas, Editorial Patria, 1994.

Ornelas Herrera, Roberto, "Radio y cotidianidad en México (1900-1930)", Pilar Gonzalbo Aizpuru, dir., Aurelio de los Reyes, coord., Historia de la vida cotidiana en México. Siglo XX. Campo y ciudad, tomo v, vol. 1, México, El Colegio de México, Fondo de Cultura Económica, 2006, 127-169.

Pérez Montfort, Ricardo, Estampas de nacionalismo popular mexicano: diez ensayos sobre cultura popular y nacionalismo, 2a edición, México, Centro de Investigaciones y Estudios Superiores de Antropología Social, 2003.

, Avatares del nacionalismo cultural: cinco ensayos, México, Centro de Investigación y Docencia en Humanidades del Estado de Morelos, Centro de Investigaciones y Estudios Superiores de Antropología Social, 2000.

Pierce, Gretchen Kristine, "Fighting Bacteria, the Bible, and the Bottle: Projects to create New Men, Women, and Children, 1910-1940", William H. Beezley, ed., A Companion to Mexican History and Culture, Malden, Wiley-Blackwell, 2011, 503-517.

Pilotti, Francisco, "Crise e perspectives da assistência à infância na América Latina”, A arte de governor crianças: A história das politicas sociais, da legislação e da assistência à infância no Brasil, Francisco Pilotti e Irene Rizzini, orgs., Río de Janeiro, Instituto Interamericano del Nińo, 1995, 25-26.

RaBy, David L. y Martha Donís, "Ideología y construcción del Estado: la función política de la educación rural en México, 19211935”, Revista Mexicana de Sociología, vol. 5, núm. 2, Visiones de México, abril-junio de 1989, 305-320. 
SÁnchez-Eppler, Karen, "Practicing for Print: The Hale Children's Manuscript Libraries", Journal of the History of Childhood and Youth, vol. 1, núm. 2, primavera 2008, 188-209. , Dependent States: The Child's Part in Nineteenth-Century American Culture, Chicago, University of Chicago Press, 2005. Sosenski, Susana, Niños en acción: el trabajo infantil en la ciudad de México, 1920-1934, México, El Colegio de México, 2010. , "Infancia y familia posrevolucionaria", Legajos: Boletín del Archivo General de la Nación, 7a época, núm. 1, julio-septiembre 2009, 10-21.

WILKIE, James W., The Mexican Revolution: Federal Expenditure and Social Change since 1910, Revised Edition, Berkeley, University of California Press, 1970.

FECHA DE RECEPCIÓN DEL ARTículo: 20 de junio de 2011 FECHA DE ACEPTACIÓN Y RECEPCIÓN DE LA VERSIÓN FINAL: 10 de octubre de 2011 